\title{
HABERMAS E A COMUNICAÇÃO IDEALIZADA
}

Luis Milman*

SÍNTESE - A Teoria da Açäo Comunicativa resulta de uma investigação acerca dos fundamentos da racionalidade prática, desenvolvida por Habermas nos últimos 30 anos. Neste artigo, serão analisados os aspectos básicos desta teoria, com ênfase nos pontos que a referenciam como modelo explanatório das nossas práticas comunicativas. Pretendo discutir prioritariamente a tese segundo a qual nossas condutas lingüisticas são conduzidas por compromissos pragmático-universais. A aceitação desta tese depende da possibilidade de explicitação dos compromissos determinantes das ações comunicativas válidas. Com base neste exame, vou propor a discussão de alguns pontos que me parecem mais frágeis na teoria de Habermas. Finalmente, pretendo contrastar este programa de reconstrução racional da comunicação com modelos teóricos pragmáticos não alinhados $a$ priori com premissas racionalistas. Concluirei, a partir dai, que o argumento central de Habermas se fragiliza quando aplicado às condiçōes multilaterais e difusas nas quais os usos da linguagem efetivamente ocorrem.
ABSTRACT - The Theory of Communicative Action is a result of the inquiry about the practical rationality foundations, developed by Jürgen Habermas in the last 30 years. In this paper I will consider the basic elements of that theory, that have been presented as a referential explanatory model for our communicative practices. I wish to examine the Habermasian argument about the reason essential pragmatic characteristics and its transcendental premiss: our usual linguistic behaviors are necessary linked to universal validity conditions. After that, a possible criticism for the Habermas global project will be sustained, by contrasting that program with some alternatives pragmatic models. The general conclusion I wish to advance from that analysis is partially negative: the Habermas' universalist thesis cannot warrant an available reconstruction of our diffuse linguistic uses.

\section{I - O percurso da razão}

A Teoria da Ação Comunicativa ${ }^{1}$ resulta de uma investigação de Jürgen Habermas, iniciada ainda na década de 60 , sobre os fundamentos da racionalidade

Universidade Federal do Rio Grande do Sul, UFRGS. Universidade de Caxias do Sul, UCS

1 A teoria empresta o nome ao livro na qual é exposta e sistematizada. A primeira edição alemã da Teoria, em dois volumes, foi publicada em 1981 pela editora Suhrkamp Verlag, de Frankfurt am Main. Neste artigo, as citações se referem a excertos da $1^{\mathrm{e}}$ tradução para o espanhol (ed. Taurus, 1987). Um terceiro volume da Teoria foi publicado por Habermas em 1991, como aditamento de estudos preliminares e complementações. Deste $3^{2}$ volume, no entanto, não constam reformulações da tese pragmático-universal discutida aqui.

\begin{tabular}{|l|l|l|l|l|l|}
\hline VERTTAS & Porto Alegre & v. 41 & $\mathrm{n}^{\circ} 162$ & Junho 1996 & p. 263-277 \\
\hline
\end{tabular}


prática. Nesta obra encontramos o modelo que ele considera apropriado para a postulação de principios racionais universais reguladores de nossas práticas comunicativas e interativas. Meu trabalho pretende destacar pontos significativos desta teoria, no que concerne aos seus marcos filosóficos. Dadas, no entanto, a abrangência e a complexidade do pensamento habermasiano, vou me limitar à exploração do argumento central de Habermas e, a partir daí, propor algumas interpretações possíveis deste argumento.

Habermas construiu uma tese sobre a natureza pragmático-comunicativa de razão, cujo ponto alto é a postulação da conexão necessária dos nossos proferimentos lingüísticos ordinários com condições de validade universais. Esta pretensa conexão, que Habermas quer tornar explicita através de seu método de análise, atualiza muitas das alegações do idealismo transcendental e da fenomenologia hegeliana, no domínio da teoria da linguagem. Pretendo discutir a validade desta atualização, em vista do que considero ser o eixo do problema pragmático de Habermas: a definição a priori do objeto da teoria.

A partir deste diagnóstico, farei algumas observações sobre a sua estratégia metodológica. Habermas assevera que o acesso aos determinantes racionais da co: municação se torna possivel se procedermos a uma reconstrução racional das práticas comunicativas. A reconstrução racional é apresentada como método que assegura certas vantagens da reflexão transcendental, mas que a ultrapassa, garantindo às suas hipóteses uma condição de cientificidade e de justificação empíricas.

O conceito de racionalidade produzido pela teoria habermasiana se fundamenta nas práticas dos sujeitos comunicativamente competentes. A racionalidade se manifesta nos consensos ou acordos obtidos pelos sujeitos que preservam tão somente regras imanentes à comunicação. Daí decorre a conseqüência mais importante da teoria da comunicação: a de que a linguagem é constrangida por padrões normativos invariantes e universais.

Considero que a distância entre este projeto e as teorias pragmáticas não alinhadas por um compromisso racionalista é muito grande. Habermas parece ter consciência disto, porque procura defender sua tese no terreno da filosofia da linguagem. Seus interlocutores preferenciais neste campo são Austin e Searle, autores de um trabalho que pode fornecer evidência às suas hipóteses. No entanto - e apesar dos esforços habermasianos - não me parece possivel sustentar um argumento pragmático-universalista nas condições multilaterais em que os usos reais da linguagem acontecem.

Esta é uma das problematizações a que se submete a Teoria da Ação Comunicativa. Por este motivo, entre outros, acredito ser importante debater o programa geral habermasiano numa perspectiva crítica. Com isto não estou pretendendo insinuar que a fragilidade do programa será assumida a priori. Penso que somente uma inspeção rigorosa do tipo de argumento que Habermas constrói pode determinar um juizo sobre a sua consistência. E mesmo que limitado pelo tempo e pelo propósito deste trabalho, estou convencido de que o debate sobre a Teoria da Ação Comunicativa é tão mais produtivo quanto mais estivermos dispostos a esquadrinhar a conclusividade deste argumento. 
Se examinarmos o desenvolvimento da obra de Habermas ${ }^{2}$ até a publicação dos dois volumes da Teoria da ação comunicativa (1981), veremos que ocorreu um redirecionamento significativo de suas teses principais e, em certa medida, até mesmo uma ruptura com os princípios metodológicos que ele defendia até o início dos anos 70. Depois do aparecimento de A crise de legitimação (1973), Habermas foi se tornando permeável às influências de programas de pesquisa não dialéticos; e reduzindo progressivamente a ênfase que colocava na inserção histórico-praxiológica da teoria e nas suas virtudes crítico-terapêuticas. Na primeira fase de seu pensamento, Habermas, então o mais brilhante representante da segunda geração da Escola de Frankfurt, priorizava a noção de teoria crítica de teoria, que ao se apropriar da realidade, supostamente liberava os instrumentos transformadores da práxis social, e desmacarava as distorções ideológicas produzidas pela expansão do capitalismo, nos planos econômico, político, cultural e psíquico.

Este Primeiro Habermas esteve envolvido num debate prolongado com a hermenêutica filosófica, uma teoria da interpretação sistematizada no cruzamento das obras de Dilthey, Heidegger e Gadamer. A hermenêutica combatia as tendências reducionistas do positivismo e da metodologia empirista aplicada à sociologia, à teoria moral e à teoria política. $\mathrm{E}$ embora com agudas discordâncias doutrinárias, crítica e hermenêutica se interpenetravam, produzindo variantes de dualismo epistêmico, historicismo e mesmo de relativismo sócio-cultural.

De um modo geral, se admitirmos que a hermenêutica filosófica enfatizava o enraizamento do intérprete em seu ambiente histórico-cultural, somos levados a concluir que o resultado da interpretação - ou da compreensão, para usarmos o termo de combate de Dilthey e de Heidegger - é definido situacionalmente: a compreensão encontra-se no plano de seu objeto. Isto quer dizer que não há acesso privilegiado, não contaminado ou não condicionado pela situação do intérprete, pela relação com sua história e tradição cultural.

Em termos epistemológicos, este enraizamento situacional tem profundas implicações relativistas. Habermas reconhecia a dimensão hermenêutica da teoria social, mas não considerava razoável abdicar da busca pelas determinações universais situadas aquém ou além das determinações historicistas ou culturalistas da vida social, incluindo-se aí as determinações que constrangem as próprias ciênciās tidas como metodologicamente mais rigorosas. Conhecimento e interesse (1968) é um texto que deve ser lido nesta perspectiva, mas com uma pequena ressalva. A compreensão neopositivista, contra a qual Habermas endereçava seus ataques mais agudos, jamais assumiu uma condição dominante na área da teoria social. $\mathrm{E}$ mesmo no plano das chamadas ciências empíricas e analíticas, o neopositivismo não sustentou sua hegemonia por muito tempo. Pelo menos desde a década de 50, depois dos trabalhos de Wittgenstein, Quine e Goodman, as questões conceituais e doutrinárias da matemática e da física têm sido submetidas a constante reexame.

2 O termo 'ruptura' tem uma aplicação restrita à mudança de orientação metodológica do pensamento de Habermas. Não houve ruptura, no entanto, com as questões substantivas que o motivaram desde 0 início. Estas foram todas preservadas durante o desenvolvimento de sua obra: o cognitivismo moral, a teleologia racionalista e a sustentação da objetividade de principios universais a priori no domínio da moralidade, da arte e da politica. 
De qualquer modo, o projeto sistemático que orientaria as preocupações habermasianas futuras estava já pré-figurado neste debate: a construção de um modelo teórico capaz de compatibilizar a pluralidade de perspectivas, formas de vida, culturas e esquemas conceituais, com princípios universalistas, e isto num ambiente filosófico acentuadamente anti-metafísico. O projeto implicava, ainda, sustentar um compromisso cognitivista-transcendental e fenomenológico, embora ajustado por concessões (sociologistas e naturalistas), diante dos padrões filosóficos antiapriorísticos dominantes no pensamento contemporâneo. Uma tarefa indiscutivelmente difícil, mesmo para o mais crítico dos racionalistas, como é o caso de Habermas.

Entretanto, o seu modo de fazer as coisas nem sempre colabora para tornar transparente esta preocupação racionalista, direcionada para a configuração de uma teoria pragmática geral da ação e da comunicação. A teoria, como tal, não apresenta muitas dificuldades de compreensão, como veremos a seguir. Mas vem precedida de uma espécie de trabalho de parto dialético, e só aparece depois de uma cansativa inspeção do pensamento sociológico, antropológico, psicológico, filosófico e lingüístico deste que tem sido um século tão vazado por aparecimentos e desaparecimentos de paradigmas conceituais. Habermas dá um nome para este trabalho de parto: reconstrução racional. Na verdade, trata-se de uma tentativa de atualizar, de um modo pretensamente não metafísico, a tarefa da crítica de Kant e da fenomenologia hegeliana. Com o recurso à reconstrução racional, Habermas acha que pode fundamentar e garantir a legitimidade da teoria do próprio Habermas. Voltarei ao tema mais adiante, mas devo antecipar que o resultado do esforço é uma sintese, uma teoria das teorias, no sentido hegeliano de um saber que percorre e supera as distintas e complementares teorias precedentes. $\mathrm{E}$ isto revela muito da concepção que Habermas tem de sua própria obra.

Reconhecer este esforço, no entanto, não é o mesmo que aceitar ou endossar o resultado do projeto habermasiano, que integra Piaget e Weber, Buhler, Austin, Searle e Rawls, Condorcet, Kant, Wittgenstein e Mead, para ficarmos só com alguns pesos pesados. Ao contrário, grande parte das debilidades desta síntese se explica pela utilização problemática e, muitas vezes, precipitada de programas científicos e filosóficos não convergentes.

O acesso à estratégia racionalista básica de Habermas e, por conseqüência, ao problema central de sua teoria, muitas vezes fica obstruído pelas discussões paralelas sobre a relevância desta exegese reconstrutiva. Gianotti, por esta razão e com grande dose de ironia, afirma que Habermas raciocina como um bricoleur (Gianotti, 1991: 7-23).

Retomando o fio de minha própria argumentação: qual é, afinal, o problema racionalista de Habermas? Eu diria que é o problema de recuperar muito de Kant e muito de Hegel em meio a um ambiente como o nosso, de tendências tão relativistas; ou ainda, o de preservar certas conquistas do transcendentalismo epistemológico por meio da asseveração, num marco sociolingüístico, de algumas condições metafisicamente necessárias da linguagem e da ação. Em Conhecimento e Interesse, Habermas tentava nos convencer da pragmatização da dedução transcendental e da necessidade de desenvolver um raciocínio reflexivo que retraçaria o caminho de volta do conhecimento às suas condiçōes invariantes de possibilidade. Neste 
texto a idéia central era demonstrar a conexão necessária da emancipação com interesses racionais a priori.

Mesmo que alguns dos pontos centrais desta teoria tenham sido revisados, e até eliminados mais tarde, nela se expressa o comprometimento com o mais radical racionalismo, que Habermas moderou em termos substantivos (substituindo o telos emancipatório pelo telos dialógico) mas que continuou mantendo com relação à ética e à política. Falo de um racionalismo radical porque é decididamente aceitável que sejamos racionalistas mas não o sejamos radicalmente. Por exemplo, podemos dizer que racionais são precisamente os constrangimentos teóricos e práticos e/ou operacionais do conhecimento; que nossas crenças são mais ou menos racionais porque são mais ou menos justificadas por estes constrangimentos, e que nossa conduta é mais ou menos racional porque determinada por crenças e desejos mais ou menos justificados. Mas isto não significa que nossos constrangimentos (teóricos ou práticos) sejam necessariamente as condições últimas e permanentes do conhecimento e da ação. Um racionalista pode desconfiar da possibilidade de uma fundamentação última e definitiva (contra Habermas) e permanecer racionalista.

Habermas é um racionalista inflexivel, linha dura. $\mathrm{E}$, em que pese a sua noção naturalizada de sujeito, este (sujeito) permanece pensado e enunciado em termos kantianos - com uma ligeira maquilagem hegeliana. Tanto isto é assim que, para Habermas, continuam atuais muitas das alegações da filosofia transcendental, principalmente aquelas que postulam a necessidade da existência de pressupostos universais da razão teórica e prática.

\section{II - A pragmática transcendental}

No âmbito da Teoria da Ação Comunicativa, podemos dizer que Habermas desdobrou o seu problema racionalista básico em quatro dimensões teórico-metodológicas:

1. a da reconstrução das situações históricas do intérprete e de seu objeto, através da formulação de uma lógica da evolução social homóloga à lógica da evolução da personalidade e do sistema cognitivo individual .

2. a da reconstrução racional do processo de socialização e de aquisição de uma competência comunicativa da espécie.

3. a da formulação de uma teoria da comunicação capaz de explicar como os determinantes estruturais pragmático-universais dão sentido à fala e às ações dos individuos.

4. a da formulação uma teoria sistêmica da sociedade capaz de apreender as conexões de significado objetivas que subjazem às intenções subjetivas e/ou que se expressam nos sistemas culturais e normativos mediatizadores das relações entre individuos e grupos.

Eu já havia afirmado que Habermas é transcendentalista de corpo e alma; mas os quatro pontos básicos da Teoria da Ação Comunicativa chamam a atenção para uma segunda característica importante de seu pensamento: a preocupação com a significância empírica da teoria. Segundo Habermas, a reconstrução das competências e das condições de ação racional não pode ser executada introspectivamente, 
porque devem refletir as estruturas genéricas da espécie. Por isso, seu conceito metodológico-chave é o de reconstrução: trata-se de um procedimento racional não apenas distinto da reflexão introspectiva, mas também distinto do método estritamente científico. A reconstrução racional, aliás, havia sido proposta por Carnap, inclusive sob a mesma designação, em 1950, para "estabelecer regras explícitas de avaliação para questões empiricamente significativas, no interior de um marco lingüístico específico". Carnap dizia que as regras que confirmam ou refutam as respostas possiveis a tais questões estão embutidas em procedimentos cognitivos de rotina. E que a tarefa de reconstruí-las "deliberada e racionalmente" cabe à "epistemologia pura, enquanto distinta da epistemologia empirica" (Carnap, 1950::205-21).

Não sei se Habermas buscou em Carnap a idéia da reconstrução racional, ou se a semelhança de perspectivas é apenas incidental. Mas devo destacar que Habermas justifica a relevância do procedimento com a alegação de que possamos competências naturais de fala e de ação, um know-how tácito de regras comunicativas, que deve ser racionalmente explicitado. $O$ diferencial da reconstrução habermasiana é a sua orientação transcendental. Na medida em que o nosso conhecimento pré-teórico e tácito, isto é, nosso domínio de competências prático-comunicativas, é um conhecimento supostamente universal, ao reconstruí-lo teoricamente estaremos explicando não só as competências universais do sujeito, como ainda as condições a priori de possibilidade do uso da linguagem e da ação.

Até aí estamos no terreno do transcendentalismo explícito. Mas Habermas não admite chamar o seu projeto de transcendental, apesar da proximidade com Kant. $\mathrm{E}$ a razão para isto é a seguinte: as reconstruções racionais não estabelecem juízos sintéticos verdadeiros a priori, ou proposições não analíticas necessariamente verdadeiras. As conclusões reconstrutivas devem ser vistas como hipóteses cientificas. Habermas as define como testáveis e passiveis de revisão; isto é o mesmo que admiti-las refutáveis pelos dados empíricos, que são os desempenhos comunicativos e práticos efetivos das pessoas, suas ações e seus proferimentos reais.

A questão que este antiapriorismo coloca para nossa abordagem é a seguinte: qual é a relação entre o método e o objeto da reconstrução racional. Se as teorias reconstrutivas não são nem teorias metafísicas, nem reconstruções lógicas (como Carnap as entendia) e se suas implicações devem ser empiricamente relevantes, 0 próprio conceito de teoria filosófica, do ponto de vista habermasiano, fica obscurecido. Por essa razão Habermas busca recursos conceituais e empíricos na sociologia, na antropologia, na economia, na psicologia e, fundamentalmente, nas chamadas ciências da linguagem, na tentativa de legitimar extrafilosoficamente o seu argumento. A idéia de uma racionalidade comunicativa, que libera pesadas implicações para a teoria moral, é desenvolvida num ambiente estritamente psico-sociológico (numa integração de Piaget, Kholberg e Weber). Não é de se estranhar, portanto, que esta pretensão à cientificidade da perspectiva reconstrucionista tenha contribuído para tornar a própria filosofia, na interpretação de Habermas, suspeita de vacuidade.

Mas é preciso ir com calma na análise desta desconfiança, pelo menos devido a três motivos elementares: Primeiro: o próprio problema habermasiano está longe de ser um problema empírico, embora se duvide que suas implicações sejam empíricas; no entanto, a postulação de umá conseqüência empirica, por si só, não 
transforma argumentos transcendentais em argumentos indutivos. Segundo: fatores metafísicos, ao nível dos princípios da própria ciência empírica, estão aí a mostrar que não há lógica capaz de, por exemplo, sustentar a posteriori o princípio da indução (rebatizado por Habermas como principio de universalização) ou o princípio da causalidade, que a ciência utiliza em todas as suas rotinas. Terceiro: raciocinar a priori é possivel em nivel não exatamente trivial e tautológico, e é isto que os filósofos fazem profissionalmente há muito tempo, mesmo que alguns não gostem de admiti-lo, talvez porque não tenham superado algumas inibições tractarianas.

$\mathrm{O}$ zelo antimetafísico de Habermas parece ser o subproduto de uma contaminação neopositivista, uma seqüela da longa convivência do autor da Teoria da Ação Comunicativa com um inimigo que, como dissemos acima, terminaria por se revelar não muito ameaçador. E não menciono esta contaminação apenas como curiosidade, uma vez que o argumento pragmático-universal de Habermas, acerca da necessidade do constrangimento racional da comunicação, mostra certa vulnerabilidade não apenas empírica, mas também filosófica.

Considerados os aspectos metodológico-reconstrutivos da Teoria da Ação Comunicativa, vamos tratar mais especificamente daquilo que Habermas chama de pragmática universal. Contra a idéia aristotélica segundo a qual, além dos chamados enunciados analíticos, apenas os enunciados constatativos são logicamente relevantes, portanto contra a idéia de que a relevância lógica sobrevém exclusivamente aos aspectos sintático e semântico da linguagem, Habermas avança a seguinte tese que vou desdobrar esquematicamente:

a) que os usos expressivo, prescritivo e expressivo da linguagem também são logicamente relevantes;

b) que esta dimensão pragmática da linguagem constitui, juntamente com as dimensões sintática e semântica, o dominio da comunicação;

c) que os aspectos pragmáticos da linguagem não são refratários à reconstrução racional;

d) que a reconstrução racional do uso da linguagem em situações comunicativas revela a racionalidade e a ética implícita aos relacionamentos interpessoais e inter-grupais;

e) que esta racionalidade e esta ética têm validade universal.

Não vou tratar desta tese exaustivamente. Mas como suas pré-condições já estão explicitadas, quero chamar a atenção para uma questão teórica significativa: a idéia de uma pragmática universal pressupõe a adoção de uma atitude contrafáti$\mathrm{ca}$, um tipo de pragmática dos mundos possíveis que nos permite considerar, ao menos, os seguintes cenários:

$1^{\text {9) }}$ um mundo possivel e falantes-ouvintes possíveis.

Neste cenário, as condições formais da racionalidade comunicativa são as seguintes: os agentes comunicativos dominam um conjunto de regras e dispõem de um estoque de universais pragmáticos (pronomes pessoais, advérbios de tempo e de lugar) que os habilitam a usar atos de fala-tipo. Estes atos de fala coordenam as relações apropriadas dos agentes com a realidade objetiva, subjetiva e social (neste caso uma realidade possivel definida pela própria teoria). Além das regras da fala, as relações institucionais e para-institucionais da comunicação ordinária e da co- 
municação científica são do tipo cooperativo, o que permite a apropriação coletiva e crítica dos critérios de ajuste ( os critérios de verdade, de autenticidade e correção) entre o que se diz, de um lado, e o que é ou deve ser, de outro. Neste mundo, as noções de razão e comunicação coincidem: razão é precisamente a possibilidade de justificação argumentativa de todos os atos de fala com base nas pretensões de validade que carregam. Desta situação interativa previamente definida decorre necessariamente a obtenção de acordos racionalmente motivados. Em última análise, os acordos particulares são objetivações de um consenso que orienta teleologicamente a comunicação (Habermas, 1981: I-369).

Formalmente a hipótese é a seguinte:

Sob certas circunstâncias teoricamente definidas $C$, agentes comunicativos idealmente definidos $A$ concordariam com $X$.

Qual é o problema com esta hipótese? Se nos convidam a imaginar aquilo que agentes idealmente racionais fariam em circunstâncias ideais, nossa resposta depende de como concebemos a natureza destes agentes e destas circunstâncias. Se ambas forem concebidas de forma a que respostas apropriadas sejam obtidas necessariamente, então o condicional contrafático aparece como justificado. Mas isto porque a hipótese foi formulada de modo a satisfazer esta condição. Pessoas idealmente racionais em situações de fala ideal só podem obter um consenso racional. Portanto, o condicional, mesmo que plausivel, requer uma outra instância de corroboração.

$2^{\mathrm{g})}$ Um mundo possivel no qual os agentes reais, em condições contrafáticas dadas, concordariam com X.

O problema com este condicional é que não temos qualquer motivo para supor que estes agentes chegariam a um consenso racional. $\mathrm{E}$ mais, temos inúmeros motivos para supor que ocorreria justamente o contrário e que eles não chegariam ao consenso, uma vez que continuariam a mostrar os vários tipos de constrangimentos que se expressam na comunicação. Importante, além disso, é não avançar uma idéia que descaracterize precisamente as condições de formação da identidade destes agentes, condições sem as quais eles sequer poderiam ser reconhecidos.

Basta com estas duas problematizações das condições de adequação postas pela teoria da racionalidade de Habermas para que cheguemos a uma conclusão importante: apesar de legítimo o uso do expediente do condicional contrafático, a maior ou menor plausibilidade das hipóteses será definida pela proximidade com as práticas interativas efetivas das pessoas. E neste caso, a única alternativa para Habermas é considerar que, numa situação de comunicação ideal, os agentes seriam diferentes a ponto de se tornarem capazes de chegar a um consenso racional. Mas se a hipótese assumisse esta feição, Habermas estaria dando por resolvido o problema de explicar como se dará a transformação dos contextos de distribuição reais do poder político e econômico. Penso que uma resposta para esta questão teórica relevante, se é que pode ser obtida, nos obrigaria a retomar a perspectiva de uma teoria social mais sintonizada com aquilo que o pensamento crítico propugnava. Mas a questão também nos coloca diante de uma dúvida: se no curso das transformações globais da sociedade, no curso de uma admitida direção da sociedade e de seus membros, sejam aqui entendidos como grupos ou como individuos, para a racionalidade em geral, estão.envolvidas transformações cognitivas e 
morais, qual é o sentido de afirmar, a não ser de um modo derivativo, que agentes sociais racionais resolvem suas disputas racionalmente? Talvez seja esta a razão pela qual Habermas dá um novo passo, em sua tentativa de justificar a necessidade de uma perspectiva sóciopragmática universalmente constringente: a elaboração de uma noção meta-empirica de pretensão de validade, de caráter claramente ordenador e indiscutivelmente ousado para quem diz assumir um pré-compromisso não transcendental.

Examinemos este passo mais detidamente. A idéia de que toda a emissão lingüistica significativa e toda a ação se conecta a uma instância que a torna válida, é até mesmo trivial. Mas o conceito de pretensão de validade de Habermas (Habermas, 1981: I-144) é mais ambicioso porque super-racionaliza as possiveis instâncias de justificação dos proferimentos lingüísticos e das ações em geral.

Num esquema explicativo pragmático aplicado à teoria do significado, por exemplo, o esquema de Grice (Grice:1968,1974), cada emissão lingüística se ajusta a um domínio de ação especifico. 0 ajuste é determinado situacionalmente, ou seja, para cada possibilidade de ação, existem circunstâncias de adequação definidas que implicam a verdade, a correção e a autenticidade da emissão/ação proferida/efetivada. Além disso, existem princípios estritamente pragmáticos de uso lingüístico ou de qualquer outro sistema representacional, como a da relevância do ato de fala, por exemplo, que, juntamente com a correlação entre proferimentos ou ações e a realidade configuram as circunstâncias empíricas de ajuste e a coerência dos proferimentos com outros proferimentos e com ações anteriores, paralelas e ulteriores, realizadas por agentes pragmaticamente competentes. Num quadro deste tipo, a afirmação de que os proferimentos e as ações possiveis estejam conectadas a pretensões de validade correspondentes é redundante. Dizer que o sujeito $S$, ao proferir a sentença $P$ pretende que $P$ seja adequada à realidade, é o mesmo que dizer que $S$ profere $P$ e acredita que $P$ é adequada (descreve um estado de coisas, ou prescreve uma ordem, etc...). Aquilo que torna $\mathrm{P}$ adequada depende de muitas coisas: da vinculação de $\mathrm{P}$ às intenções ou desejos e às crenças de $\mathrm{S}$ e de como as coisas são acreditadas ser num sistema de crenças que $\mathrm{S}$ compartilha com sua cultura, para ficarmos num nível bastante genérico. Assim, a expressão pretensão de validade daria conta da coerência do proferimento de $\mathrm{P}$ com a malha de interações que determina formal e empiricamente a sua adequação situacional. Temos assim o esboço de um esquema pragmático-relacional que nos proporciona uma teoria do significado e que conecta a linguagem ao mundo por meio de uma série de mediações de ordem ontológica, psicológica e sociológica definidas a posteriori.

Já a noção habermasiana de pretensão de validade se instaura a partir de uma tarefa mais ambiciosa: a de provar que nossas emissões lingüísticas mais singelas e nossas ações mais corriqueiras estão sobredeterminadas racionalmente; que uma leitura reconstrutiva da realidade comunicativa é capaz de tornar visíveis os compromissos de nossas rotinas com certos fins cognitivos e normativos universais; e ainda: que situações comunicativas ideais (definidas como domínios discursivos não constrangidos por motivações contingentes) conduzem os participantes a um consenso racional acerca do que é verdadeiro e justo, sob todos os pontos de vista. Sob este prisma, uma teoria da comunicação necessariamente deve pressupor a validade a priori de condições a partir das quais a comunicação ideal é possivel. 
Isto nos faz deparar novamente com o problema de explicar a distância entre 0 que é possível e o que permanece como prática efetiva de agentes comunicativos reais. Mas Habermas não considera que o argumento da realidade refuta o argumento da possibilidade. Ao tratar, por exemplo, dos limites das teorias pragmáticas empíricas (a exemplo da teoria de Grice), ele aponta sempre para o mesmo defeito: são todas vítimas de um enfoque particularista, que deriva para o pluralismo e o relativismo. Incapazes, portanto, de perceberem nos jogos de linguagem e na rede de atos de fala, a dinâmica de padrões normativos universais e constringentes.

Parece-me ser precisamente por esta razão que, do ponto de vista de Habermas, a comunicação é o universo mais favorável à construção de uma teoria da racionalidade, já que nela certas regularidades mais recorrentes e certos padrões de uso mais enraizados nas práticas da espécie estão supostamente mais evidenciados. E são esses os padrões que Habermas projeta nos demais universos de interação, de modo a torná-los, com maior ou menor ênfase, passiveis de uma apropriação estritamente racional.

Uma vez justificada a escolha do locus ideal da razão, Habermas elege o marco apropriado para o desenvolvimento de sua Teoria da Ação Comunicativa: os trabalhos de Austin sobre os atos de fala (Austin, 1962), que ele considera a matriz conceitual para uma teoria geral do uso da linguagem. Sabemos que Austin introduz a noção de speech act para destacar o fato de que as pessoas, ao proferirem sentenças, estão também realizando ações e não apenas se reportando a eventos ou estados de coisa. Austin dividia os atos de fala em três tipos: o locucionário, o ilocucionário e o perlocucionário. Mas na perspectiva de Habermas, esta tipologia não funciona apenas como classificação a posteriori dos vários tipos de ação lingüística; ela também revela a estrutura, a forma da ação comunicativa, ou seja, da ação orientada para o entendimento interpessoal. Esta ação comunicativa, cuja forma pode ser apreendida pela pragmática universal, fundamenta a tese racionalista de fundo segundo a qual a razão pertence essencialmente à comunicação.

$\mathrm{O}$ que dizer do aspecto formal desta tese? Habermas aqui adota o esquema de Searle (Searle, 1969) que ampliou o horizonte de Austin: a forma de qualquer proferimento performativo é $F(p)$, onde $F$ é o sinal para 'força ilocucionária' e $p$ o sinal para uma proposição. $\mathrm{O}$ aspecto que Austin chamava de 'ilocucionário' e que Searle designava de 'força ilocucionária' revela, num plano teórico, os pontos que as abordagens clássicas da linguagem desprezavam, ao considerá-los fatores meramente psicológicos e contingentes da linguagem.

Não há muito o que acrescentar sobre o conteúdo proposicional de um ato de fala, do ponto de vista da pragmática de Habermas. Suas discussões acerca da natureza da proposição são apenas tangenciais, porque a ênfase da análise é posta sobre a estrutura dupla da performance lingüística. Este é um ponto que muitos comentadores de Habermas - especialmente aqueles que adotam seus pontos de vista - não consideram decisivo. Mas a 'questão proposicional' merece um comentário a mais, por uma razão importante. As teorias pragmáticas do significado não estão condicionadas estritamente pelos aspectos extra-proposicionais da linguagem, como a perspectiva de Habermas sugere. Há uma profusão de usos lingüísticos em que apenas proposições e circunstâncias de enunciação estão envolvidas, mas cujo significado só é passível de um resgate pragmático. Pensemos nas ambi- 
güidades intencionais ou não (ambigüidades contextualmente eliminadas), no uso de indexadores espaciais e temporais, nos operadores modais e de ênfase, que acompanham nossos proferimentos lingüísticos. Estes aspectos são, digamos, semântico-pragmáticos, porque determinam a apreensão do significado intersubjetivo e contextual dos proferimentos lingüísticos.

Também não podemos esquecer que a própria relação de referência da linguagem, com seus problemas epistemológicos e ontológicos sistematicamente debatidos, está na matriz da revisão da teoria do significado tradicional, do tripé FregeRussel-1 Wittgenstein. A pragmática, como disciplina que teoriza sobre a relação entre sentenças e suas condições subjetivas e objetivas de uso, não se desenvolveu à margem destas discussões semânticas. Por isso, as fronteiras entre a semântica $e$ a pragmática (se é que existem) são mais tênues do que a perspectiva de Habermas faz supor.

Como não posso me deter aqui na discussão de todos os pontos que mencionei, quero apenas registrar o seguinte: apesar de ser apresentada como uma teoria geral da comunicação, a pragmática universal de Habermas é, em muitos aspectos reducionista e, em muitos outros aspectos, superficial. Se isto a torna metodologicamente desinteressante, não é uma questão que pode ser respondida facilmente. No que me concerne, creio que Habermas poderia, mesmo no terreno restrito da análise dos atos de fala, defender uma tese pragmático-formal consistente, não fossem os compromissos transcendentais que seu programa assume.

\section{III - Ações idealizadas e pretensões de validade}

Habermas afirma que todo ato de fala possui dois niveis de articulação; e que os agentes comunicativos são capazes de interação precisamente porque possuem a competência de articular/decifrar estes niveis em cada proferimento que emitem ou interpretam. Os niveis são o da intersubjetividade, com base no qual falante e ouvinte comunicam-se um com o outro, e o nivel objetividade, sobre o qual falante e ouvinte podem chegar a um entendimento relativo aos fatos.

Esta é uma descrição simplificada do que ocorre quando duas pessoas conversam. Mas a mera descrição não explica o que torna a comunicação possível. Assim, a questão que, para Habermas, permanece sem resposta, é como os atos de fala podem resultar no estabelecimento de relações intersubjetivas? Como um ato de fala pode produzir um vínculo, um compromisso, que garanta o prosseguimento de ações, entre o falante e o ouvinte?

Ele responde fazendo uma distinção, ainda no interior do modelo de AustinSearle, entre compromissos externamente determinados e compromissos imantes aos atos de fala. Os primeiros derivam de convenções sociais e normas estabelecidas e produzem um efeito perlocucionário. Por exemplo, quando se ordena algo a alguém, em função da existência de um sistema de normas e sanções que constrange o destinatário ao cumprimento da ordem, mesmo quando esta é imprópria. O segundo tipo produz um efeito ilocucionário, uma resposta não constrangida por fatores externos, mas pela força das próprias razões postas pela emissão (Habermas, 1981: I-376-88). Efeitos ilocucionários são perseguidos pelos falantes quando motivados pelo entendimento recíproco e pela busca de um consenso racional, isto 
é, de um consenso estritamente determinado por razões e não por coações. Daí a definição de ações comunicativas como "interações mediatizadas lingüisticamente, nas quais todos os participantes perseguem, com seus atos de fala, fins ilocucionários e somente fins ilocucionários" (Habermas 1981: I-378). Os fins perlocucionários são remetidos a contextos das ações estratégicas, a saber, de interações nas quais os fins perseguidos são determinados por interesses contingentes dos falantes.

Mas o que significa, num contexto de ação comunicativa, entender um ato de fala? Habermas identifica aqui entendimento como aceitabilidade racional intersubjetiva. Um ouvinte aceita um ato de fala quando este cumpre as condições necessárias para que a resposta do destinatário seja afirmativa. E estas condições pressupõem que falante e ouvinte "reconheçam a pretensão lingüística [...] que estabelece um acordo, especificado com relação a seu conteúdo, e determina as obrigações relevantes para a interação posterior" (Habermas, 1981:I-382). A base racional que subjaz à força ilocucionária de um ato de fala consiste no seu vínculo a quatro pretensões de validade distintas subjacentes à comunicação:

(a) o falante, com seu ato de fala, implicitamente pretende que o mesmo seja inteligível;

(b) que o conteúdo proposicional do ato seja verdadeiro;

(c) que o componente performativo seja correto e

(d) que suas intenções, sentimentos ou desejos sejam sinceros.

Essas quatro pretensões de validade constituem a base para a obtenção do consenso em nossos jogos de linguagem cotidianos. Mais importante, ainda, é salientar que o consenso é motivado racionalmente, isto é, a qualquer momento uma ou mais pretensões de validade podem ser submetidas à crítica durante o intercurso comunicativo. Assim, uma ordem pode ser questionada no que concerne à sua adequação normativa, uma descrição, no que concerne à sua adequação aos fatos, etc... . Essas práticas funcionam como as garantias da asseveração dos atos de fala em situações interativas reguladas exclusivamente pela força do melhor argumento. Apenas são racionalmente justificadas as ações que se submetem e resistem à crítica sistemática de suas pretensões de validade.

\section{IV - Uma possível crítica}

Vários autores têm questionado a consistência e os pressupostos deste esquema, em vista das conseqüências racionalistas, idealizantes e conciliatórias que 0 esquema impõe no planos político, ético e epistemológico. Na primeira parte de minha exposição tratei de considerar alguns pontos básicos (e alguns pontos frágeis) do projeto racionalista global habermasiano, ligados a estes questionamentos. Não retornarei a eles agora. Quero, no entanto, destacar três objeções fortes à teoria de habermasiana:

19. Não podemos associar simultaneamente a todos os atos de fala as quatro pretensões de validade, tal como Habermas pretende que façamos. Quando contamos uma piada a alguém, o significado do que é dito não depende sequer de sua plausibilidade. Ou ainda, quando dizemos constatativamente que o cão está sobre o tapete e o cão está sobre o tapete, em que sentido está sendo pressuposta uma pretensão normativa? A exigência de tornar, as pretensões de validade simultanea- 
mente necessárias é tão demasiada, que se a levássemos a sério seríamos forçados a atribuir aos nossos proferimentos propriedades que simplesmente eles não têm.

Além disso, a própria exigência de alinhar nossos proferimentos a pretensões de validade previamente definidas encurta demasiadamente a dimensão comunicativa. No caso dos atos de fala indiretos, como as insinuações e alusões, a validade é determinada pela relevância do proferimento no contexto e não à verdade ou à correção normativa.

Há inúmeros exemplos deste tipo que poderíamos listar. Mas a conclusão a que chegamos sobre este déficit na pragmática habermasiana é a seguinte: ou bem o déficit pode ser explicado pela teoria, (com a alegação de que estes proferimentos são apenas formas subsidiárias de comunicação, meras instâncias derivativas da ação orientada ao entendimento) ou bem a classificação dos atos de fala tipos (constativos, regulativos, expressivos e de comprometimento) aplica-se apenas a um âmbito restrito da comunicação, o que parece-me ser o caso.

$2^{\circ}$ Não podemos aceitar sem discussão a afirmação de que o consenso é imanente à comunicação. E mesmo se a aceitássemos, nada nos garantiria que estaríamos imunes à possibilidade de obtenção de consensos racionais acerca de teorias não verdadeiras. No terreno da ética e da política, a relação entre consenso e justiça, por exemplo, reforça ainda mais este problema. Há incontáveis exemplos em nossa história, da existência de consensos sobre condutas, individuais e coletivas, acentuadamente injustas e condenáveis.

$3^{\circ}$ A tese mais forte de Habermas é a tese da identidade entre razão e comunicação. Se observarmos bem, esta tese se depara com problemas diante da constatação, feita pelo próprio Habermas, de que, na instância da comunicação estratégica, a ação dominante é a ação racional calculativa, ou seja, aquela que avalia os meios necessários para a obtenção de fins. Habermas parece atribuir a esta instância uma racionalidade de nivel inferior. Digo 'parece atribuir' porque ele não nos dá motivos para pensar que a ação estratégica não seja racional. Modelos teoréticos de escolha racional, que conhecemos desde Aristóteles, com seu silogismo prático e que estão na base da distinção kantiana entre os imperativos hipotéticos e os categóricos, se fundamentam no princípio de que a propriedade de 'ser racional' é atribuída a ações justificadas por fins subjetivos e/ou objetivos. E que a discussão dos fins, ou seja, a discussão acerca de que valores devem orientar as ações, esta sim é decisiva do ponto de vista da determinação ou da escolha dos meios.

Mesmo que permaneçamos no domínio das ações comunicativas, o problema da racionalidade nos coloca o seguinte dilema, se raciocinarmos de acordo com Habermas: podem dois indivíduos agir racionalmente, defendendo cada um a pretensão de validade de seu argumento num ambiente discursivo, e assim mesmo fracassarem na obtenção de um acordo? Se podem, o conceito de racionalidade não se define pelo conceito de 'ação comunicativa', já que a prática da argumentação racional é no máximo uma condição necessária, mas não uma condição suficiente para superar impasses morais e políticos, por exemplo (para não mencionar os impasses metateóricos, ontológicos e metodológicos da própria ciência).

Talvez o melhor a fazer, nestas questões, seja adotar critérios de não-aceitação de condutas desviantes, individuais ou coletivas, fundamentadas em nossa tradição cultural e em nossa metodologia científica. E aceitar conviver com condutas 
diferentes que não coloquem em risco tais critérios valorativos. Mas neste caso estaríamos tomando uma decisão em favor de determinada concepção ética e política, em detrimento de outras concepções existentes e, no mínimo, possivelmente racionais.

Não posso me estender na discussão deste tema, mesmo porque não estou certo de ser capaz de convencê-los a adotar o meu ponto de vista moderadamente racional. Mas acredito que Habermas comete neste ponto um grave equivoco. $\mathrm{Na}$ medida em que pretende resolver, na teoria da linguagem, os problemas da razão prática, ele se compromete a universalizar pontos de vista morais e epistêmicos consensuais da tradição e da cultura que produziu a sua linguagem e a sua moralidade.

Além disto, as supostas simetrias formais que ele acredita estarem na base de todas as situações de fala (mesmo que isto ocorra apenas no plano de uma situação de fala teoricamente construída), não são suficientes para determinar a escolha entre visões racionais e alternativas de mundo, para não mencionar as disputas onde estão em jogo interesses não manifestos, demandas de poder e o exercício da dominação. Esta incapacidade é sintomática da discrepância que há entre o formalismo excessivo e o reducionismo transcendental da teoria da ação comunicativa, de um lado, e os problemas práticos aos quais ela supostamente deveria se aplicar, de outro.

Para concluir: uma teoria da comunicação deve ser capaz de explicar o que torna possiveis os diversos usos da linguagem, em situações de emprego reais e de distribuição simétrica e assimétrica dos papéis, os chamados agentes comunicativos. Por este motivo, acredito que as pragmáticas formais levam uma vantagem apreciável sobre os projetos que definem o seu objeto a priori. A universalidade das estruturas subjacentes à fala, pretendida pela pragmática de Habermas, não pode ser estabelecida indutivamente, pela simples razão de que não são características da comunicação em todas as culturas e em todas as épocas e, como temos repetido, nem mesmo características dominantes da comunicação em nossa própria sociedade. Mesmo o esforço metodológico realizado por Habermas para tornar aceitável a diferença entre hipóteses produzidas via generalizações empíricas e hipóteses resultantes de uma reconstrução racional, mantém esta questão inalterada.

Assim, se a pragmática universal é, como quer Habermas, uma ciência empírico-reconstrutiva que persegue um tipo de saber a posteriori; se tais reconstruções devem apreender as estruturas e regras de fato operativas nas práticas comunicativas; e se estas estruturas são encontradas, com alguma freqüência apenas, em certas áreas de certas culturas, durante um certo periodo de tempo, então como é possivel sustentar - e não meramente postular - a tese de que se trata realmente de estruturas pragmáticas universais da comunicação? 


\section{Referências bibliográficas}

HABERMAS, Jürgen, Theorie und Praxis - Darmstadt-Neuwied: Herman Luchterhand Verlag, 1963 (trad. esp. Teoria y Praxis, Madrid: Ed. Tecnos, 1987).

- Erkenntnis und Interesse, Frankfurt am Main: Suhrkam Verlag, 1968 (trad. bras. Conhecimento e Interesse, Rio de Janeiro: Zahar, 1982).

— . Technik und Wissenschaft als "Ideologie", Frankfurt am Main: Suhrkamp Verlag, 1968 (trad. port. Técnica e Ciência como Ideologia, Lisboa: Edições 70, 1987).

- Logik der Sozialwissenschaften, Frankfurt am Main: Suhrkamp Verlag, 1970, (trad. ing. Logics of Social Sciences, Boston: Beacon Press, 1973).

— . Zur Reconstruktion Des Historischen Materialismus, Frankfurt am Main: Suhrkamp Verlag, 1976 (trad. esp. La Reconstrucción del Materialismo Histórico, Madrid: Taurus, 1981).

- Theorie Des Kommunikativen Handelns, dois vol., Frankfurt am Main: Suhrkamp Verlag, 1981 (trad. esp. Teoría de La Acción Comunicativa, Madrid: Taurus, 1987).

- Moralbewusstsein und kommunikatives Handeln, Frankfurt am Main: Suhrkamp Verlag, 1983 (trad. bras. Consciência Moral e Agir Comunicativo, Rio de Janeiro: Tempo Brasileiro, 1989).

- Nachmetaphysisches Denken, Frankfurt am Main: Suhrkamp Verlag, 1988 (trad. bras. Pensamento Pós-Metafísico, Rio de Janeiro: Tempo Brasileiro, 1990).

CARNAP, Rudolf. "Empiricism, Semantics and Ontology". In: International Philosophical Review, 4, 1950, p. $20-40$.

AUSTIN, John L. How To Do Things With Words, Oxford, 1962.

SEARLE, John. Speech Acts, Cambridge, 1969.

- Expression and Meaning: Studies in the theory of speech acts, Cambridge, 1979.

HELD, D; THOMPSON, J. (eds), Habermas: Critical Debates, Cambridge, Mass., MIT Press, 1982.

Mc CARTHY, Thomas. The Critical Theory of Jürgen Habermas, Cambridge, Mass., MIT Press, 1985.

GIANOTTI, J. A. "Habermas: Mão e Contramão". In: Novos Estudos-Cebrap, 31, São Paulo, 1991.

GRICE, H. P., "Utterer's Meaning, Sentence Meaning and Word Meaning". In: Foundations of Language, 4. 1968.

1974, III.

DASCAL, Marcelo. Pragmatics and The Philosophy of Mind, Amsterdam: John Benjamins, 1983. 